\title{
The social impact of partial edentations in a group of young adults
}

\author{
Impactul social al edentaţii lor parţiale la un lot de adulţi tineri
}

\author{
George Ion', Dan Cosmin Şerbănoiu², Mariana Păcurar², Rodica Luca' ${ }^{1}$ \\ ${ }^{1}$ Facultatea de Medicină Dentară, UMF „Carol Davila“, Bucureşti, România \\ ${ }^{2}$ Facultatea de Medicină Dentară, U.M.F.S.T. Tg. Mureş, România
}

\begin{abstract}
Aim. To analyze the social impact of partial edentulism in young adults. Material and method. 300 patients, divided into two groups: group 1 (age 18-25) and group 2 (age 26-35), who presented at least one partial edentation completed a two-part questionnaire. The first part included socio-demographic data (age, sex, place of residency, education level) and the second part questions about how the presence of a possible front edentation could influence the individual's relationship with family, friends, couple life, or employment chances. The answers were analyzed according to the socio-demographic variables. Statistical processing was done with SPSS 13.0 for Windows.

Results. For both groups statistically significant differences between the level of education and the employment opportunities were obtained $(p<0.05)$. In group 1 , the place of residency influenced relationships with friends and couple life, whereas in group 2 the most influenced were the couple's life and the chances of employment.

Conclusions. In both age groups of young adults the presence of a partial edentulism had a negative social impact on the quality of life.
\end{abstract}

Keywords: partial edentulism, young adult, quality of life

\section{REZUMAT}

Scop. Analiza impactului social al edentaţiilor parţiale la adultul tânăr.

Material şi metodă. 300 de pacienţi cu vârste între 18 şi 35 de ani care au prezentat cel puţin o edentaţie parţială au completat un chestionar alcătuit din două părţi. Prima parte a cuprins întrebări privind datele sociodemografice (vârsta, sex, mediu de provenienţă, nivel de educaţie), iar partea a doua întrebări despre cum prezenţa unei posibile edentaţii frontale ar putea influenţa relaţia individului cu familia, prietenii, viaţa de cuplu sau şansele la angajare. Răspunsurile la partea a doua a chestionarului au fost interpretate în funcţie de variabilele socio-demografice. Prelucrarea statistică s-a făcut cu programul SPSS 13.0 for Windows.

Rezultate. Pacienţii au fost împărţiţi în două loturi: lotul 1 (vârste între 18 şi 25 de ani) şi lotul 2 (vârste între 26 şi 35 de ani). La ambele loturi s-au obţinut rezultate semnificative statistic între nivelul de educaţie şi afectarea şanselor la angajare $(p<0,05)$. La lotul 1 , mediul de provenienţă a influenţat relaţia cu prietenii şi viaţa de cuplu, iar la lotul 2 viaţa de cuplu şi şansele la angajare.

Concluzii. La adultul tânăr, în ambele grupuri de vârstă analizate, prezenţa unei edentaţii parţiale a avut un impact social negativ asupra calităţii vieţii.

\section{Cuvinte cheie: edentaţie parţială, adult tânăr, calitatea vieţii}

\section{INTRODUCERE}

Studiul calităţii vieţii joacă un rol din ce în ce mai important în îngrijirile de sănătate oro-dentară. Pentru a obţine o imagine completă a stării de sănătate orală, pe lângă metodele clasice de evaluare ce includ indicii dentari clinici, este necesar să se evalueaze şi impactul afecţiunilor orale asupra calităţii vieţii.

Prezenţa edentaţiilor, indiferent de cauză sau localizare, contribuie la scăderea calităţii vieţii (1-3), afectând atât masticaţia şi fonaţia, cât şi aspectul fizic, în relaţie directă cu influenţarea relaţiilor sociale ale individului cu familia, prietenii sau viaţa de cuplu. În multe cazuri, scăderea încrederii în sine şi afectarea relaţiilor sociale sunt mai importante pentru pacient decât complicaţiile edentaţiei (4).

Obiectivele OMS privind afecţiunile odontale, parodontale şi pierderea prin extracţii dentare sunt focalizate pe grupele de vârstă: 6 ani, 12 ani, 18 ani, 35-44 de ani sau $>65$ de ani, intervalul 18-35 de ani 
(grupă de vârstă atribuită pentru prima oară adultului tânăr de psihologul Erik Erikson la începutul anilor '60) (5) fiind mai puţin studiat (6). Acesta este motivul pentru care am ales special grupa de vârstă 18-35 de ani, precum şi pentru a analiza implicaţiile sociale pe care le poate determina o edentaţie frontală.

\section{MATERIAL ŞI METODĂ}

În studiu (de tip cross-sectional) au fost incluşi toţi pacienţii cu vârste cuprinse între 18 şi 35 de ani, care au solicitat asistenţă stomatologică în perioada 2015-2018 în două cabinete stomatologice, unul din mediul urban (Bucureşti), al doilea din mediul rural (jud. Ilfov). Criteriul de includere în studiu a fost reprezentat de prezenţa a cel puţin unei edentaţii, indiferent de localizarea acesteia, şi de acceptul şi semnarea consimţământului informat. Pacienţii au fost împărţiţi în două loturi de câte 150 , primul lot cu vârsta cuprinsă între 18 şi 25 de ani (lotul 1), al doilea cu vârsta între 26 şi 35 de ani (lotul 2).

Fiecare pacient, căruia i s-a întocmit o foaie de observaţie în care a fost consemnat statusul odontal, a fost rugat să completeze un chestionar prin metoda interviului faţă în faţă (7). Chestionarul, cu întrebări de tip închis, a cuprins două părţi. În prima parte au fost întrebări privind datele socio-demografice (vârsta, sex, mediu de provenienţă, nivel de educaţie), iar în partea a doua, întrebări despre cum prezenţa unei posibile edentaţii frontale ar putea influenţa relaţia individului cu familia, prietenii, viaţa de cuplu sau şansele la angajare. Datele obţinute au fost centralizate şi răspunsurile la partea a doua a chestionarului au fost interpretate în funcţie de variabilele socio-demografice. Pentru prelucrarea statistică (crosstabs, testul chi-pătrat şi Pearson) s-a folosit programul SPSS- Statistical Package for the Social Sciences 13.0 for Windows. Valoarea minimă a pragului de semnificaţie statistic folosit a fost $\mathrm{p}=0,05$.

\section{REZULTATE}

În cadrul primului lot de studiu, cu vârsta cuprinsă între 18 şi 25 de ani (vârsta medie 21,88 de ani), 45 (30\%) pacienţi au fost de sex masculin şi $105(70 \%)$ au fost de sex feminin. În cadrul celui de-al doilea lot, cu vârste cuprinse între 26 şi 35 de ani (vârsta medie 30,19 de ani), participarea a fost de $87(58 \%)$ de sex masculin şi 63 (42\%) de sex feminin (tabel 1). Nu au existat diferenţe semnificativ statistic între sexul pacienţilor în niciunul din cele două loturi ( $\mathrm{p}=0,766$ respectiv $\mathrm{p}=0,856)$.

TABELUL 1. Distribuția pacienților din cele două loturi în funcție de sex şi nivelul de educație

\begin{tabular}{|c|c|c|c|c|c|c|c|c|}
\hline $\begin{array}{c}\text { Nivel de } \\
\text { educație }\end{array}$ & \multicolumn{4}{|c|}{ Lot 1 } & \multicolumn{4}{c|}{ Lot 2 } \\
\hline & \multicolumn{2}{|c|}{ masculin } & \multicolumn{2}{|c|}{ feminin } & masculin & \multicolumn{2}{c|}{ feminin } \\
\cline { 2 - 10 } & $\mathrm{n}$ & $\%$ & $\mathrm{n}$ & $\%$ & $\mathrm{n}$ & $\%$ & $\mathrm{n}$ & $\%$ \\
\hline gimnaziu & 3 & 6,66 & 4 & 3,81 & 7 & 8,06 & 8 & 12,7 \\
\hline liceu & 25 & 55,55 & 54 & 51,43 & 42 & 48,27 & 29 & 46 \\
\hline studii & 17 & 37,79 & 47 & 44,76 & 38 & 43,67 & 26 & 41,3 \\
superioare & & & & & & & & \\
\hline total & 45 & 100 & 105 & 100 & 87 & 100 & 63 & 100 \\
\hline
\end{tabular}

Ca nivel de educaţie, primul lot cuprindea 7 pacienţi $(4,66 \%)$ ce au absolvit gimnaziul, 79 $(52,66 \%)$ liceul, iar $64(42,66 \%)$ au avut studii superioare; în lotul al doilea, 15 pacienţi $(10 \%)$ au absolvit gimnaziul, $71(47,33 \%)$ liceul, iar cei cu studii superioare au fost în număr de 64 (42,66\%) (Tabelul 1). În figura 1 este prezentată distribuţia pacienţilor din ambele loturi în funcţie de sex şi mediul de provenienţă.

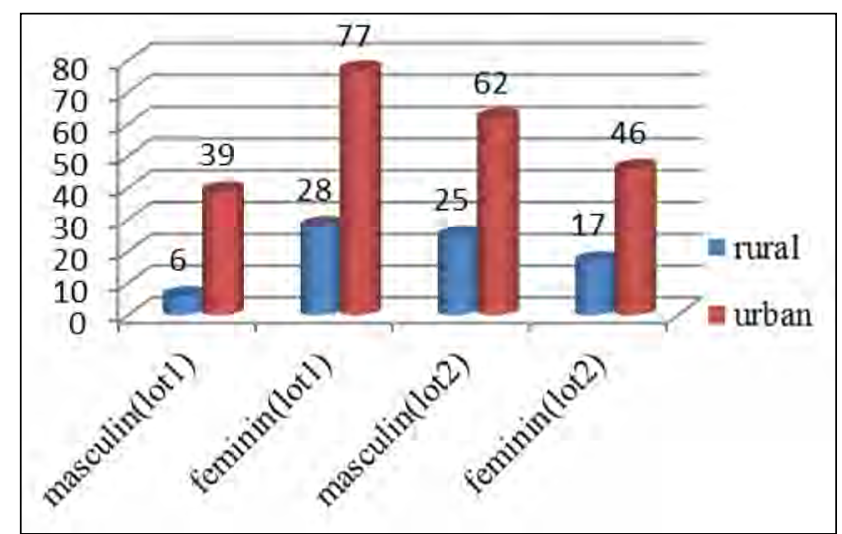

FIGURA 1. Distribuția pacienților în funcție de mediul de proveniență

În ceea ce priveşte corelaţiile statistice (folosind testul chi pătrat şi Pearson) între variabilele reprezentate de mediul de provenienţă, sexul şi nivelul de educaţie al pacienţilor şi posibila afectare a relaţiilor cu familia, prietenii, viaţa de cuplu sau şansele la angajare ale pacienţilor în eventualitatea unei edentaţii frontale, rezultatele sunt ilustrate în tabelele nr. 2 şi 3 (rezultate semnificativ statistic fiind cele în care $\mathrm{p} \leq 0,05)$. 
TABELUL 2. Corelatii între variabile pentru lotul 1

\begin{tabular}{|c|c|c|c|c|}
\hline & $\begin{array}{c}\text { relația cu } \\
\text { familia }\end{array}$ & $\begin{array}{c}\text { relația cu } \\
\text { prietenii }\end{array}$ & $\begin{array}{c}\text { viata de } \\
\text { cuplu }\end{array}$ & $\begin{array}{c}\text { şansele la } \\
\text { angajare }\end{array}$ \\
\hline sex & $\mathrm{p}=0,723$ & $\mathrm{p}=0,216$ & $\mathrm{p}=0,874$ & $\mathrm{p}=0,623$ \\
\hline $\begin{array}{c}\text { mediu de } \\
\text { proveniență }\end{array}$ & $\mathrm{p}=0,236$ & $\mathbf{p}=\mathbf{0 , 0 5}$ & $\mathbf{p}=\mathbf{0 , 0 5}$ & $\mathrm{p}=0,061$ \\
\hline $\begin{array}{c}\text { nivel de } \\
\text { educație }\end{array}$ & $\mathrm{p}=0,557$ & $\mathrm{p}=0.985$ & $\mathrm{p}=0,593$ & $\mathrm{p}=\mathbf{0 , 0 0 1}$ \\
\hline
\end{tabular}

TABELUL 3. Corelații între variabile pentru lotul 2

\begin{tabular}{|c|c|c|c|c|}
\hline & $\begin{array}{c}\text { relatia cu } \\
\text { familia }\end{array}$ & $\begin{array}{c}\text { relatia cu } \\
\text { prietenii }\end{array}$ & $\begin{array}{c}\text { viata de } \\
\text { cuplu }\end{array}$ & $\begin{array}{c}\text { sansele la } \\
\text { angajare }\end{array}$ \\
\hline sex & $p=0,757$ & $p=0,815$ & $p=0,909$ & $p=0,612$ \\
\hline $\begin{array}{c}\text { mediu de } \\
\text { proveniență }\end{array}$ & $p=0,365$ & $p=0,142$ & $p=0,043$ & $p=0,011$ \\
\hline $\begin{array}{c}\text { nivel de } \\
\text { educație }\end{array}$ & $p=0,993$ & $p=0,492$ & $p=0,412$ & $p=0,049$ \\
\hline
\end{tabular}

În cazul ambelor loturi s-au obţinut rezultate semnificativ statistice între nivelul de educaţie şi afectarea şansele la angajare în cazul unei edentaţii frontale $(p<0,05)$. În cazul lotului 1 , mediul de provenienţă a influenţat relaţia cu prietenii şi viaţa de cuplu, în cazul lotului 2, mediul de provenienţă a influenţat viaţa de cuplu şi şansele la angajare.

\section{DISCUȚII}

Starea de sănătate şi percepţia calităţii vieţii sunt în strânsă legătură cu o serie de factori socio-demografici precum mediul de provenienţă, nivelul de venit al pacientului, gradul de educaţie. Dar nu toţi factorii socio-demografici sunt în directă relaţie cu percepţia calităţii vieţii (prin diversele componente), de exemplu variabila „vârstă“, fiind ştiut faptul că pacienţii mai tineri pun accentul pe un grad mai ridicat al fizionomiei/aspectului fizic, faţă de cei din categorii mai mari de vârstă, care sunt mai interesaţi de funcţionalitatea aparatului dento-maxilar (8). Tocmai datorită acestui motiv, în studiul nostru am dorit să evidenţiem modul în care adultul tânăr percepe implicaţiile pe care le are o edentaţie parţială frontală pe plan social. Scăderea satisfacţiei faţă de calitatea vieţii şi mulţumirea faţă de starea de sănătate sunt invers proporţionale cu creşterea vârstei pacienţilor (9).

Din totalul pacienţilor care au solicitat tratament stomatologic în perioada 2015-2018 în cadrul celor două cabinete (unul din Bucureşti, celălalt din jud. Ilfov), au fost selectaţi 300 pacienţi ce prezentau cel puţin o edentaţie parţială, indiferent de localizarea ei, fiind împărţiţi în două categorii de vârstă: lotul 1: 18-25 de ani, preponderent au fost cei de sex masculin 105 (70\%), lotul 2: 26-35 de ani, pacienţii de sex feminin fiind în număr de 87 (58\%).

În ceea ce priveşte distribuţia pacienţilor în funcţie de mediu de provenienţă, în ambele loturi au predominat pacienţii din mediul urban, în lotul 1 numărul pacienţilor de sex feminin fiind aproape dublu faţă de cei de sex masculin, în lotul 2 distribuţia fiind relativ echilibrată. Cei cu un nivel mediu de educaţie (liceu) s-au întâlnit în 74\% dintre cazuri în lotul 1, în lotul 2 cei cu studii medii (47\%) fiind relativ egali cu cei cu studii superioare (42\%).

Ca observaţii generale, în cazul existenţei unei posibile edentaţii frontale, la ambele subgrupe de vârstă analizate, variabila sex nu a influenţat relaţia individului cu familia, prietenii, viaţa de cuplu sau şansele la angajare. De asemenea, niciunul dintre factorii socio-demografici analizaţi nu a influenţat relaţia individului cu familia. În schimb, au existat diferenţe între cele două subgrupe de vârstă în privinţa modului în care mediul de provenienţă şi nivelul de educaţie au influenţat relaţia individului cu prietenii, viaţa de cuplu sau şansele la angajare. Astfel, la pacienţii din lotul 1, mediul de provenienţă a influenţat relaţia cu prietenii şi viaţa de cuplu, în timp ce, la pacienţii din lotul 2, odată cu creşterea grupei de vârstă, relaţia cu prietenii nu a mai fost influenţată, dar, pe lângă viaţa de cuplu, a fost influenţată şi şansa la angajare $(p<0,05)$.

În privinţa nivelului de educaţie, la pacienţii din ambele loturi, acesta a avut influenţă semnificativă statistic asupra şanselor de angajare. Totuşi, la pacienţii din lotul 1, influenţa nivelului de educaţie a fost mult mai mare $(\mathrm{p}<0,001)$ comparativ $\mathrm{cu}$ pacienţii din lotul $2(p<0,049)$. Extrapolând oarecum aceste rezultate semnificative statistic între variabila nivel de educaţie şi afectarea şanselor la angajare, putem considera că nivelul de educaţie ar putea influenţa calitatea vieţii. De altfel, în literatura de specialitate se arată că gradul de educaţie, prin nivelul de cunoştinţe mai crescut sau mai scăzut în ceea ce priveşte domeniul medical, poate influenţa calitatea vieţii şi prin rolul pe care îl are în influenţarea stării de sănătate/sănătatea oro-dentară a individului $(10,11)$.

\section{CONCLUZII}

Edentaţia parţială, în cazul studiului de faţă edentaţia frontală, are un important impact social 
(în calitate de componentă a calităţii vieţii). În cele două intervale de vârstă analizate (18-25, 26-35 de ani), relaţia cu familia, viaţa de cuplu, relaţia cu prietenii, şansele de angajare au fost influenţate în mod diferit în funcţie de sexul pacientului, de mediul lui de provenienţă şi nivelul de educaţie.

\section{BIBLIOGRAFIE}

1. McGrath $C$, Bedi R. Can dentures improve the quality of life of those who have experienced considerable tooth loss? Journal of Dentistry, 2001. 29(4): p. 243-6.

2. Gerritsen AE, Allen PFi, Witter DiJ, Bronkhorst EM, Creugers NHJ. Tooth loss and oral health-related quality of life: A systematic review and meta-analysis. Health and Quality of Life Outcomes, 2010. 8(1): p. 126.

3. Steele JG, Sanders AE, Slade GD, Allen Pk Fi, Lahti S, Nuttall N et al. How do age and tooth loss affect oral health impacts and quality of life? A study comparing two national samples. Community dentistry and oral epidemiology, 2004. 32(2): p. 107-14.

4. Okoje VN, Dosumu OO, Alonge TO, Onyeaso C. Tooth loss: Are the patients prepared? Nigerian journal of clinical practice, 2012. 15(2): p. $172-5$.

5. Erikson EH, Erikson JM. The life cycle completed (extended version). 1998: WW Norton \& Company.p. 61.

6. Hescot $P$, Roland E. Dental health in France in 1998. French Union of Dental Health (UFSBD) Report. Paris: UFSBD, 1993.
Pentru reducerea impactului social al edentaţiei parţiale şi, implicit, pentru creşterea calităţii vieţii adultului tânăr, sunt necesare programe de prevenţie pentru minimalizarea apariţiei stării de edentat parţial.
7. Organization World Health, ed. Oral Health Surveys Basic Methods. 5th ed. 2013, World Health Organization. p. 113

8. Murariu A, Hanganu C. Oral health and quality of life among 45-to 64-year-old patients attending a clinic in lasi, Romania. Oral Health and Dental Management in the Black Sea Countries, 2009. 8(2): p. 7-11.

9. Murariu A, Hanganu C, Vasluianu R. Eurobarometru - Aprecierea calităţi vieţii la nivel populaţional. Romanian Journal of Medical and Dental Education. Vol. 2, Issue 2, 2013: p. 57-62.

10. Pop CE. Starea de sănătate a populaţiei din România în context european. $\mathrm{O}$ abordare din perspectiva calităţii vieţii. Revista Calitatea Vieții, 2010. 21(3-4): p. 274-305.

11. Tsakos G, Sheiham A, lliffe S, Kharicha K, Harari D, Swift CG et al. The impact of educational level on oral health-related quality of life in older people in London. European journal of oral sciences, 2009. 117(3): p. 286-92. 